Jurnal Informatika dan Rekayasa Perangkat Lunak (JATIKA)
Vol. 1, No. 1, June 2020, 83-92

\title{
Analisis Implementasi Metode Sprint dalam Pengembangan Aplikasi Multiplatform
}

\author{
Elfin Sanjaya ${ }^{1}$, Muhammad Bakri ${ }^{2}$ \\ SIInformatika ${ }^{1,2}$ (Universitas Teknokrat Indonesia)
}

elfinsanjaya1207@gmail.com 1,,muhammadbakri@ teknokrat.ac.id²

Received: (Juni 2020)Accepted: (Juni 2020) Published: (Juni 2020)

\begin{abstract}
The needs of Indonesian fabric are fairly large, and this is certainly an opportunity for local fabric sellers and one of them is Fabric Store. At present, Fabric Store conducts general marketing through online media, such as the Whatsapp Group, Instagram, and also various well-known online stores such as Shopee and Tokopedia. As customers' interests develop, Fabric Store develops new business processes with a loyalty point system. However, there is no system that can be used for this. In the Shopee application and also Tokopedia, Fabric Store has a major problem, which is asynchronous stock in the application with the existing stock in the warehouse because the admin often forgets to update the application if there are transactions done offline. Of the existing problems, multiplatform applications are needed that can help Fabric Store. This application will be built using a centralized data system. Multiplatform applications must be completed in a fast time, for that use the Sprint method and validation using expert judgment. By using the Sprint method, it is expected that the application can be completed in a short and measurable way. In addition, it is expected that the application can facilitate customers in the transaction
\end{abstract}

Keywords: Centered Data, Expert Judgement, Multiplatform, Sprint Method, Transctions.

\begin{abstract}
Abstrak
Kebutuhan kain penduduk Indonesia terbilang besar, dan hal ini tentunya menjadi peluang bagi penjual kain lokal dan salah satunya adalah Fabric Store. Saat ini, Fabric Store melakukan pemasaran secara umum melalui media online, seperti Grup Whatsapp, Instagram, dan juga berbagai toko online ternama seperti Shopee dan Tokopedia. Seiring dengan berkembangnya minat para pelanggan, makan Fabric Store mengembangkan proses bisnis baru dengan sistem poin loyalitas. Namun, belum ada sistem yang dapat digunakan untuk ini. Pada aplikasi Shopee dan juga Tokopedia, Fabric Store memiliki permasalahan utama, yaitu tidak sinkronnya stok pada aplikasi dengan stok yang ada di gudang karena seringkali admin lupa untuk melakukan pembaruan pada aplikasi jika ada transaksi yang dilakukan secara offline. Dari permasalahan yang ada, dibutuhkan aplikasi multiplatform yang dapat membantu Fabric Store. Aplikasi ini nantinya akan dibangun dengan menggunakan sistem data yang terpusat. Aplikasi multiplatform harus diselesaikan dalam waktu yang cepat, untuk itu digunakan metode Sprint dan validasi menggunakan expert judgement. Dengan menggunakan metode Sprint, diharapkan aplikasi dapat diselesaikan dengan singkat dan terukur. Selain itu juga, diharapkan agar aplikasi dapat memudahkan pelanggan dalam bertransaksi.
\end{abstract}

Kata Kunci: Data terpusat, Expert Judgement, Metode Sprint, Multiplatform, Transaksi.

\section{To cite this article:}

Elfin Sanjaya, Muhammad Bakri. (2020 Analisis Implementasi Metode Sprint dalam Pengembangan Aplikasi Multiplatform. Jurnal Informatika dan Rekayasa Perangkat Lunak, Vol(1), 83-92.

\section{PENDAHULUAN}

Indonesia memiliki kebutuhan akan kain yang cukup besar. Menurut data yang ada, Indonesia masih mengimpor kapas sebagai bahan baku sekitar 99.2\% dari total kebutuhan kapas nasional per tahun (Kemenperin, 2019). Hal ini menjadi suatu potensi yang besar bagi penjual kain di Indonesia. Fabric Store adalah salah satu penjual kain lokal yang berdomisili di daerah Bandar Lampung yang memasarkan kain secara online dan juga offline. Saat ini Fabric Store sedang mengembangkan proses bisnisnya menjadi proses bisnis yang baru. Salah satunya ialah dengan menggunakan poin loyalitas bagi pelanggan. Namun, Fabric Store masih menggunakan 
sistem dari pihak ketiga untuk proses penjualannya, sehingga masih terjadi masalah selisih stok karena data yang tidak terpusat. Aplikasi yang dimaksudkan adalah aplikasi pendataan stok barang. Permasalahan lainnya, Fabric Store menggunakan beberapa platform aplikasi seperti web dan mobile. Aplikasi yang dibutuh oleh Fabric Store harus mendukung multiplatform. Platform mobile digunakan bagi pelangganuntuk melihat katalog dan juga membeli barang. Sedangkan, platform web digunakan oleh admin untuk mendata stok dan juga mengunggah katalog bagi pelanggan. Aplikasi juga bersifat online dan terpusat sehingga memudahkan pendataan stok barang

Untuk itu, dibutuhkan aplikasi multiplatform yang dapat menyesuaikan dengan kebutuhan yang ada pada Fabric Store. Platform mobile digunakan bagi pelanggan untuk melihat katalog dan juga membeli barang. Sedangkan, platform web digunakan oleh admin untuk mendata stok dan juga mengunggah katalog bagi pelanggan. Pengembangan aplikasi ini membutuhkan metode yang tangkas dan cepat agar dapat menyelesaikan bentuk jadi aplikasi dalam waktu yang singkat, karena aplikasi yang akan dibangun merupakan aplikasi yang bersifat multiplatform dan kompleks. Berdasarkan penelitian yang telah dilakukan, metode Sprint yang dikembangkan oleh Google Ventures merupakan metode yang dapat diimplementasikan dengan cepat dan juga berfokus pada pemecahan masalah. Metode ini dapat diterapkan pada semua pengembangan aplikasi yang mengutamakan menyelesaikannya dalam waktu lima hari (Raubenolt, 2016). Dengan menggunakan metode Sprint, diharapkan aplikasi dapat diselesaikan dengan singkat dan terukur. Selain itu juga, diharapkan agar aplikasi dapat memudahkan pelanggan dalam bertransaksi.

\section{TELAAH PUSTAKA}

\section{Sprint}

Sprint adalah proses unik dari Google Ventures yang terdiri dari 5 hari untuk menjawab pertanyaan krusial melalui prototyping dan menguji ide dengan customer (Knapp, Zeratsky, Kowitz, 2016). Sprint merupakan strategi bisnis, inovasi, desain yang sangat hebat dan dikemas menjadi langkah- langkah yang dapat diterapkan dalam tim mana pun.

Tahapan Sprint adalah sebagai berikut:

Hari Senin : Melakukan pemetaan (mapping)

Hari Selasa : Membuat sketsa $($ sketch)

Hari Rabu : Mengambil keputusan (decide)

Hari Kamis : Membuat rancang bangun (prototype)

Hari Jumat : Melakukan pengujian (test)

\section{Platform Aplikasi}

Platform desktop, web, dan mobile adalah 3 platform terbesar yang digunakan saat ini (Czernicki, 2009). Ketiga jenis platform ini melingkupi mayoritas dari platform UI di luar sana. UI pada desktop biasanya lebih interaktif. Sedangkan UI pada web biasanya memiliki standar dan menyediakan pengalaman multimedia yang kaya. Perangkat mobile biasanya lebih kecil dan memiliki konten yang lebih sederhana. Setiap platform digunakan secara berbeda-beda dan untuk itulah didesain secara berbeda.

\section{Node.js}

Node.js adalah server-side platform yang dibangun dengan Google Chrome Javascript Engine (V8 Engine). Node.js pertama kali dikembangkan oleh Ryan Dahl tahun 2009. Node.js bersifat open source, yaitu bebas digunakan secara gratis dan juga bisa digunakan di berbagai platform (cross-platform) seperti Windows, Linux, atau Mac. Node.js ditulis menggunakan Javascript dan menyediakan berbagai macam library Javascript yang mempermudah dalam pengembangan aplikasi (Tua, 2018).

\section{ExpressJS}

ExpressJS merupakan framework minimal yang sangat fleksibel. ExpressJS dapat digunakan untuk membuat web server HTML, server file statik, aplikasi chat, search engine, social media, layanan web dengan akses melalui REST API atau aplikasi hybrid, yaitu pengguna mempunyai akses melalui REST API juga mempunyai akses ke HTML page. 


\section{Expert Judgement}

Expert Judgement pertama kali dikembangkan di Rand Corporation Amerika Serikat pada tahun 1948, untuk menemukan stategi militer, yang melibatkan ahli perang, seni tempur, sosiolog, psikolog. Kerena keberhasilanya, pengembangan selanjutnya Expert Judgement banyak digunakan oleh para perencana program pendidikan, teknologi, transportasi, pemasaran, kesehatan dan manajemen informasi dalam proses pengambilan keputusan. Expert Judgement (pertimbangan ahli) adalah suatu cara pendekatan yang bersifat intuitif untuk mengorganisasikan ide-ide atau pemikiran diantara para pakar, para ahli untuk membahas (mengatasi masalah) lembaga atau masyarakat pada masa yang akan datang (Soenarto, 2005).

\section{METODE PENELITIAN}

\section{Kerangka Pemikiran}

Kerangka pemikiran yang melandasi penelitian yang dilakukan dapat dilihat pada Gambar 1 berikut :

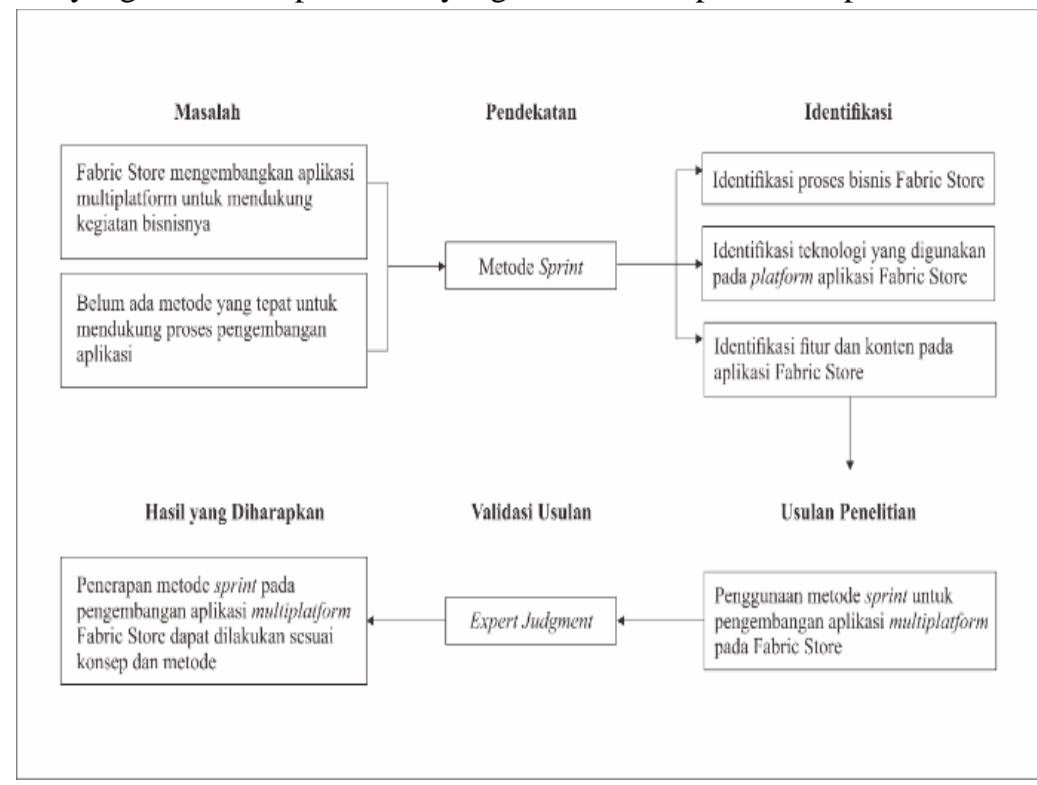

Gambar 1. Kerangka Pemikiran

\section{Kerangka Pengujian}

Metode pengujian yang digunakan dalam penelitian ini ialah menggunakan interview dan juga menanyakan pada expert yang sesuai dengan bidangnya (expert judgement), setelah itu melakukan perbaikan terhadap aplikasi sesuai saran yang diberikan pada surat pernyataan expert judgement.

Skenario pengujian yang akan dilakukan adalah:

1) Mempersiapkan prototype yang telah dibangun.

2) Mengumpulkan 5 orang expert di bidang penelitian ini, dapat berupa owner dan juga ahli di bidang mobile app atau web.

3) Mencatat hasil evaluasi dari expert sebagai bahan perbaikan aplikasi.

\section{Teknik Pengumpulan Data}

Pengumpulan data yang akan dilakukan pada penelitian ini adalah sebagai berikut:

1. Observasi

Pengumpulan data dengan cara mengadakan penelitian dilapangan dengan mengamati kondisi yang terjadi dilapangan, dalam hal ini penulis melakukan observasi pada Fabrik Store

2. Wawancara

Metode ini dilakukan dengan cara tanya jawab atau wawancara kepada karyawan dan owner mengenai permasalahan yang dibahas.

3. Identifikasi 
Bertujuan untuk mencari, menemukan, mengumpulkan, meneliti dan mencatat informasi terkait kebutuhan penelitian, yang mengenai penelitian terdahulu seperti definisi masalah dan lingkup penelitian.

\section{Identifikasi Masalah}

1. Proses Bisnis Fabrik Store

Fabrik Store melakukan penjualan di beberapa marketplace seperti Shopee dan Tokopedia selain itu Fabrik Store juga memanfaatkan media sosial seperti Instagram dan aplikasi bertukar pesan Whatsapp.

2. Kebutuhan Fungsional

Kebutuhan fungsional merupakan kebutuhan berupa data-data yang di butuhkan untuk menginputkan dari sistem, berikut adalah kebutuhan fungsional:

a. Dapat melihat informasi produk

b. Dapat melakukan transaksi pembelian

3. Kebutuhan Non-Fungsional

Kebutuhan non fungsional merupakan kebutuhan berupa perangkat-perangkat pendukung yaitu sistem dapat di jalankan di Perangkat atau Platform Android 5.0 (lollipop).

\section{HASIL DAN PEMBAHASAN Implementasi Model Sprint}

Penerapan model sprint dilakukan pada tim yang beranggotakan 5 orang dengan spesialisasi sebagai berikutTabel .

\section{Tabel 1. Anggota Tim Sprint}

\begin{tabular}{|l|l|}
\hline Spesialiasi & Tugas Pokok \\
\hline Desainer UX & $\begin{array}{l}\text { Membuat desain aplikasi } \\
\text { Membuat protipe aplikasi }\end{array}$ \\
\hline Backend Programmer & Membuat API server untuk Mobile Aplikasi dan Backoffice. \\
\hline Decider & Mengambil keputusan untuk TIM. \\
\hline Fasilitator & Mengatur jalannya sprint dan memimpin meeting \\
\hline Mobile Programmer & Membuat Aplikasi Mobile Fabrik Store untuk customer \\
\hline Front-end programmer & Membuat Aplikasi Backoffice untuk admin Fabrik Store \\
\hline
\end{tabular}

\section{Pemetaan Tujuan (Goal Mapping)}

Adapun hasil pemetaan Goal maping dimana memusatkan seluruh kegiatan penjualan tekstil melalui aplikasi Fabrik StoreMultiplatfrom.

1. Goal Mapping

mapping goal dapat dilihat pada gambar berikut.

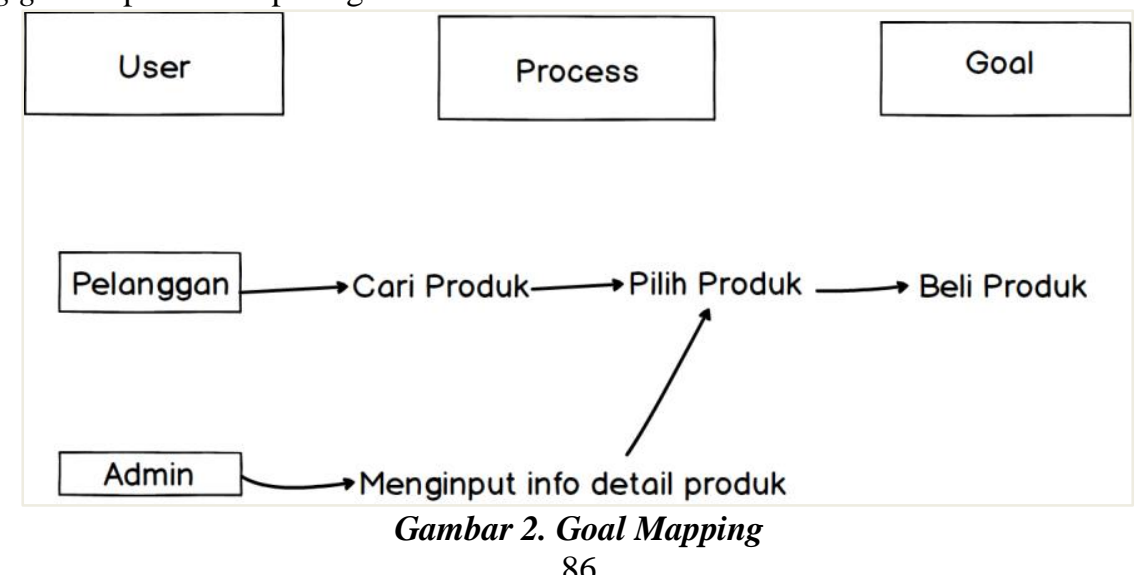




\section{Ask the Expert}

Hasil dari kegiatan Ask the Expert adalah daftar HMW dapat dilihat pada Tabel berikut.

Tabel 2. Tabel HMW Note

\begin{tabular}{|l|l|}
\hline \multicolumn{1}{|c|}{ Ask the Expert } & \multicolumn{1}{|c|}{ HMW Note } \\
\hline $\begin{array}{l}\text { Pelanggan ragu untuk membeli produk karena info } \\
\text { yang tersedia pada sosial media kurang lengkap. }\end{array}$ & $\begin{array}{l}\text { Bagaimana menyediakan aplikasi yang dapat } \\
\text { memuat informasi lengkap mengenai produk kepada } \\
\text { pelanggan? }\end{array}$ \\
\hline $\begin{array}{l}\text { Sebelum melakukan pembelian, pelanggan } \\
\text { cenderung bertanya kepada seller mengenai biaya } \\
\text { pengiriman }\end{array}$ & $\begin{array}{l}\text { Bagaimana menyediakan aplikasi yang dapat } \\
\text { meningkatkan self service pelanggan? }\end{array}$ \\
\hline $\begin{array}{l}\text { Sebagian besar pelanggan belum mengetahui cara } \\
\text { berbelanja melalui aplikasi. }\end{array}$ & $\begin{array}{l}\text { Bagaimana menyediakan sebuah aplikasi commerce } \\
\text { yang mudah digunakan bahkan bagi pelanggan yang } \\
\text { gagap terhadap teknologi? }\end{array}$ \\
\hline
\end{tabular}

\section{Membuat sketsa (Sketch)}

Adapun hasil dari skech dimana terdapat terdapat beberapa kegiatan sebagai berikut :

1. Lighting demo

Hasil dari lighting demo dapat dilihat pada Tabel berikut:

Tabel 3.Llighting Demo

\begin{tabular}{|l|l|}
\hline \multicolumn{1}{|c|}{ Shopee } & Zilingo \\
\hline Tampilan dan konten pada detail produk & Tampilan antarmuka (UI) yang sederhana \\
\hline
\end{tabular}

2. Crazy Eight

Hasil dari Crazy Eightdapat dilihat pada gambar berikut.

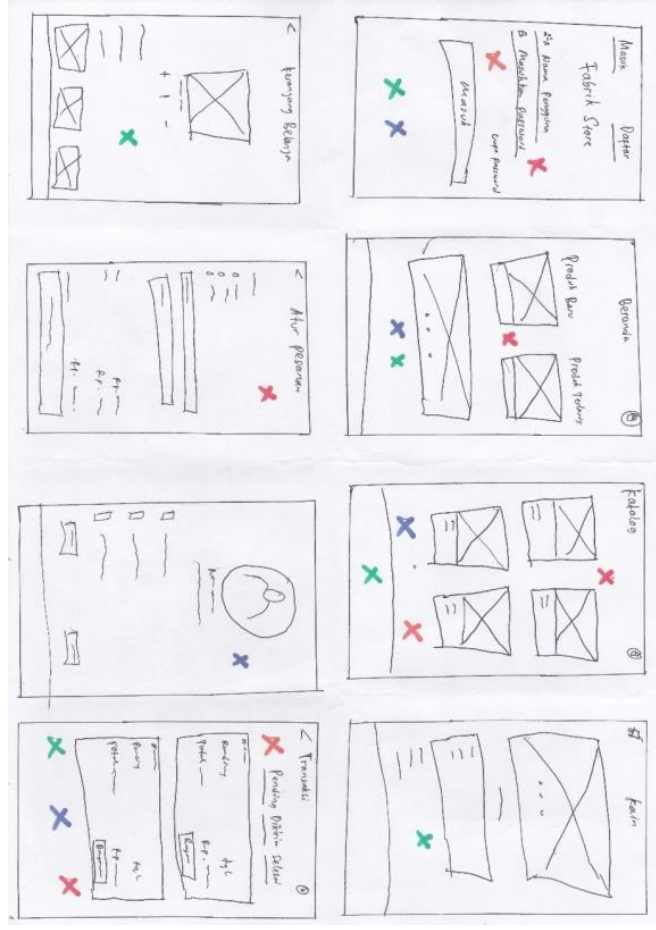

Gambar 3. Crazy Eight

\section{Sketsa Solusi}

Hasil dari Sketsa Solusi dapat dilihat pada gambar berikut. 

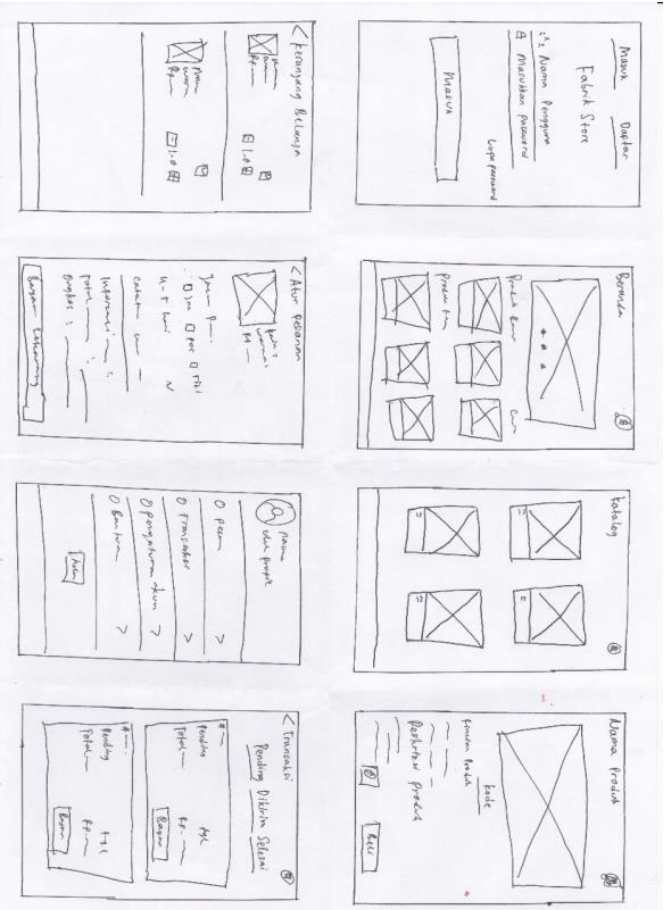

Gambar 0. Sketsa Solusi

\section{Mengambil Keputusan (Decide)}

Adapun hasil dari Decide dimana semua kegiatan di gabung menjadi satu berupa storyboard dari pemilihan sketsa solusi dan rumble or all in one seperti pada gambar berikut.

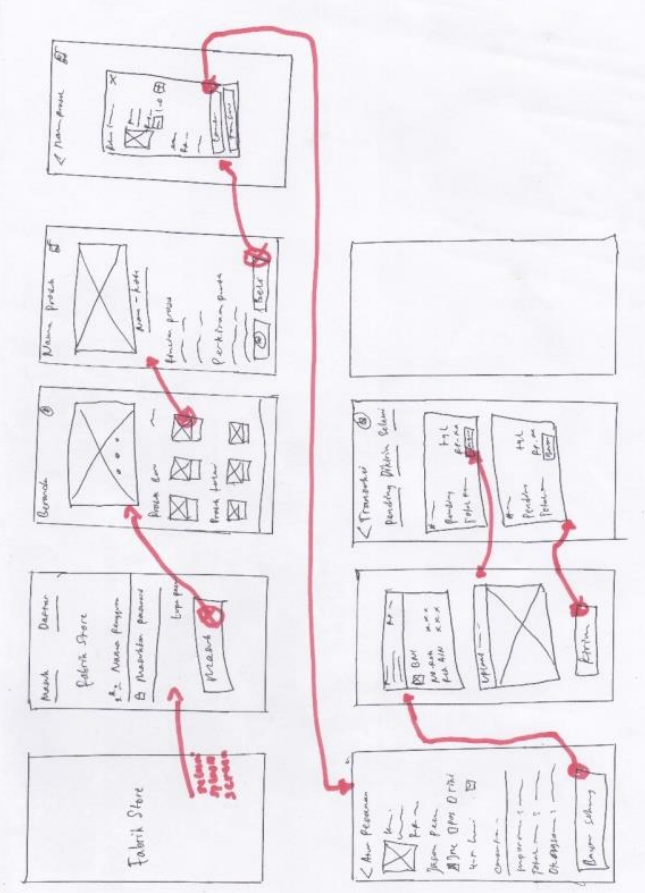

Gambar 5. Story Board 


\section{Membuat rancang bangun (Prototype)}

Hasil dari tahapan ini dapat dilihat pada gambar berikut :

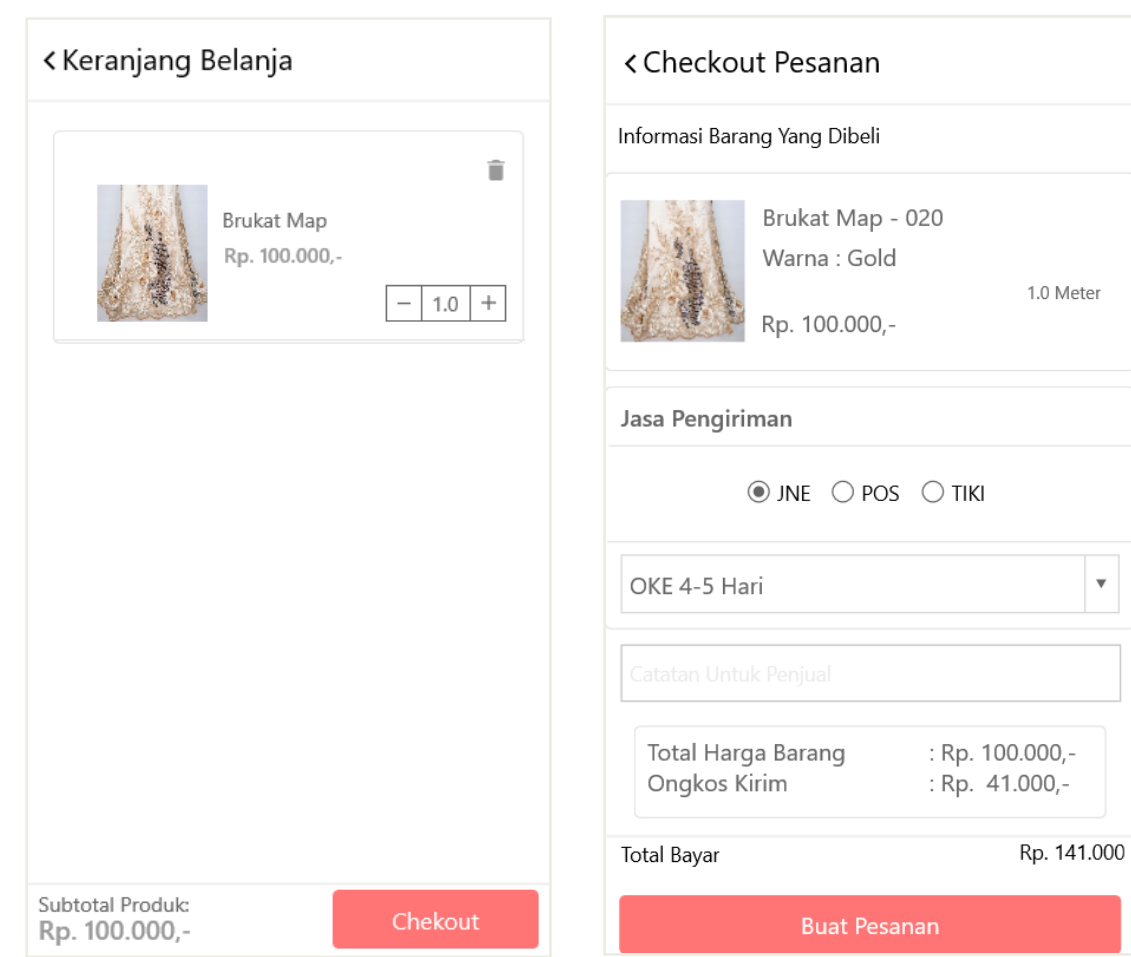

Gambar 6. Tampilan prototype Keranjang Belanja dan Checkout pesanan

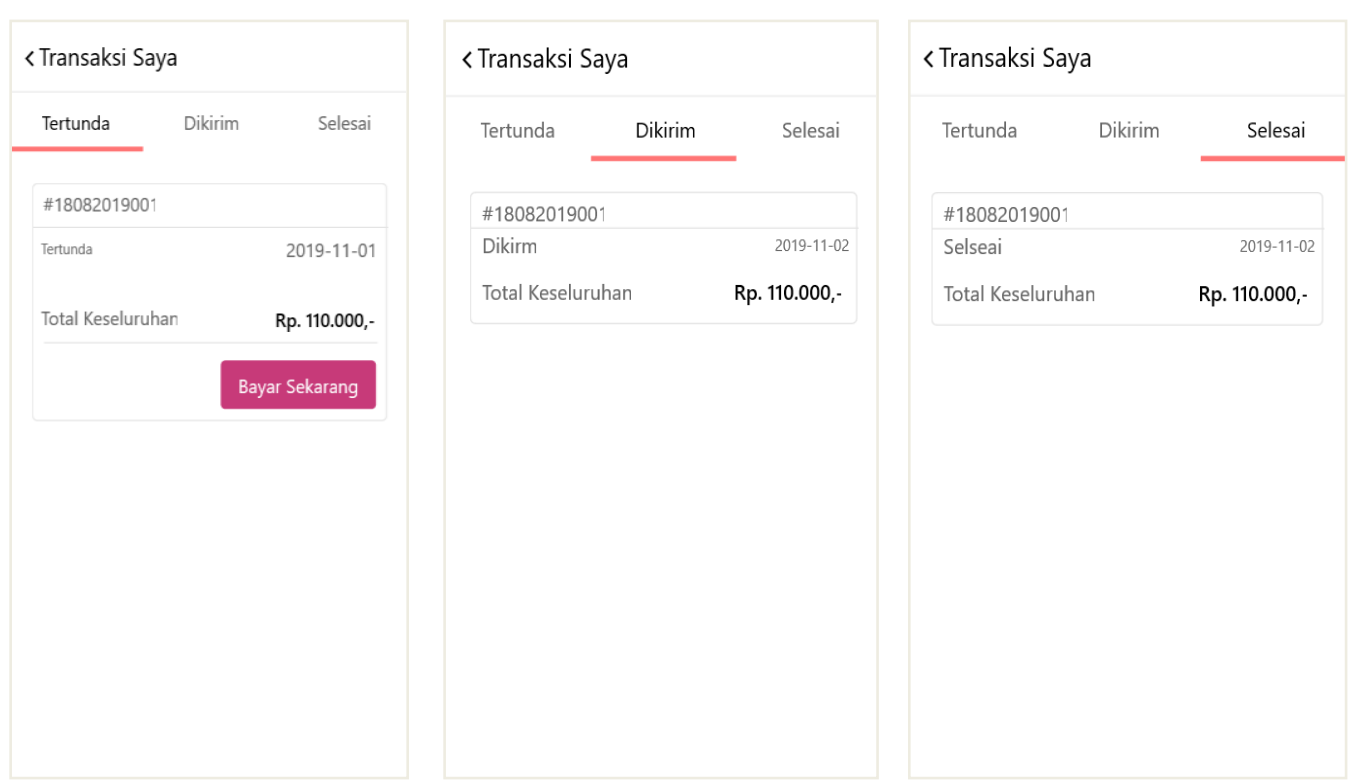

Gambar 7. Tampilan prototype Transaksi dan Status transaksi 


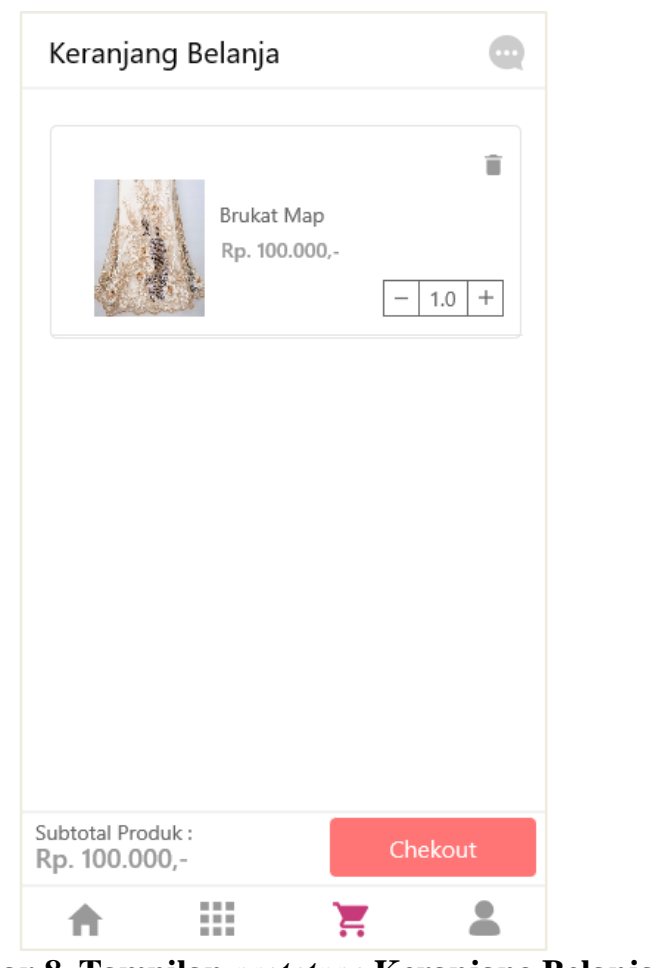

\section{Melakukan Pengujian (Test)}

Hasil dari Test berupa kesimpulan dari responden dapat dilihat pada gambar berikut.

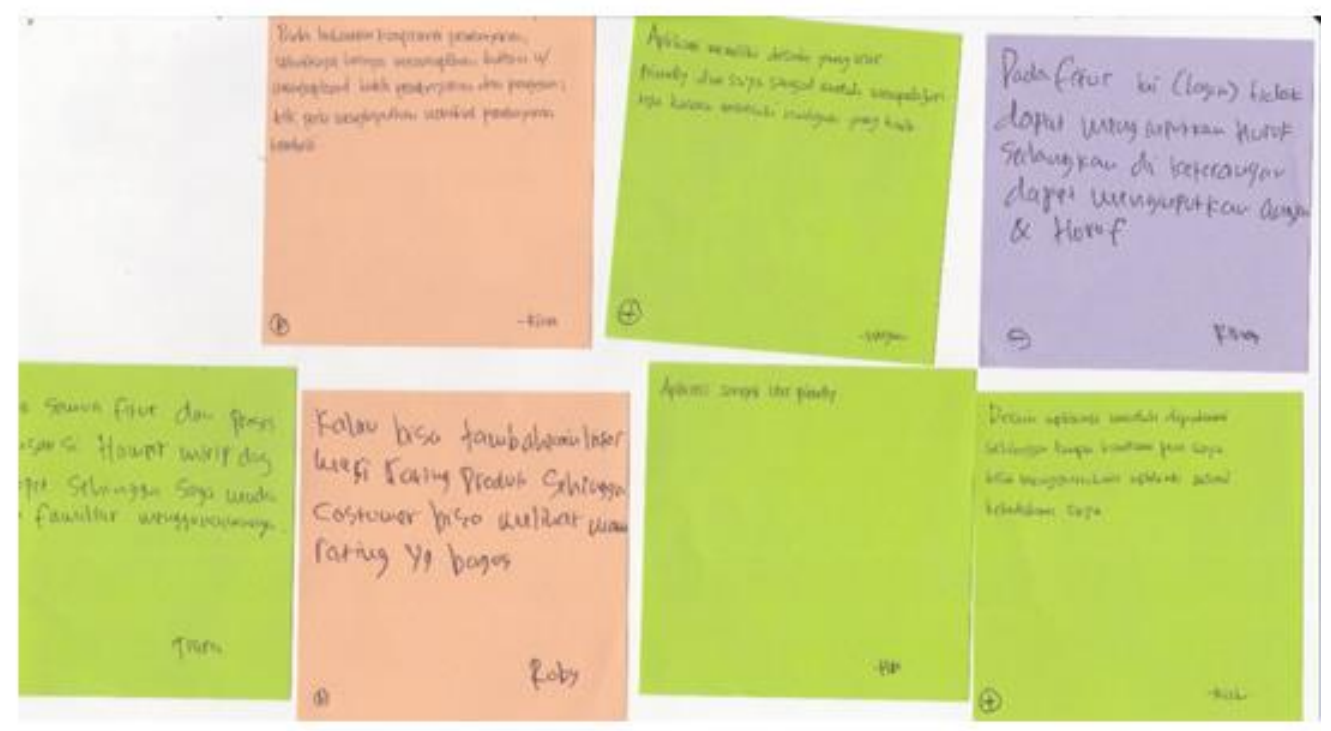

Gambar 8. Hasil Testing

Kesimpulan yang diambil oleh decider berdasarkan pengujian yang telah dilakukan terhadap 5 orang responden ialah. Prototype aplikasi dapat diterima dengan beberapa catatan dan perbaikan untuk kemudian masuk dalam tahap pengembangan yaitu penulisan kode program. 


\section{Pengujian}

Guna mengukur kecocokan metode sprint dalam pengembangan aplikasi multiplatform, menggunakan expert judgement sebagai refrensi pengujian metode sprint.

Adapun penjelasan mengenai alur pengujian expert judgment yaitu:

1. Membuat dokumen teknis yang berisi kegiatan sprint selama 5 hari.

2. Setelah membuat dokumen teknis penulis menyerahkan kepada expert judgment kemudian diminta untuk mengecek selama kegiatan sprint selama 5 hari.

3. Tahapan terakhir dari pengujian adalah expert judgment diminta menyimpulkan hasil pengujian.

\section{Skenario Pengujian (Scenario)}

Skenario pengujian yang akan dilakukan adalah:

1. $\quad$ Melihat hasilkegiatan pada hari pertama sprint (mapping)

2. Melihat hasilkegiatan pada hari kedua sprint (skecth)

3. Melihat hasil kegiatan pada hari ketiga (decide)

4. Melihat hasilkegiatan pada hari kedua sprint (prototype)

5. Melihat hasil kegiatan pada hari kelima sprint (test)

\section{Dokumentasi Hasil Pengujian}

Seorang ahli diminta untuk memeriksa hasil dari dokumen teknis.Kemudian, menyimpulkan bahwa kegiatan yang dilakukan selama 5 hari tersebut valid atau tidak valid. Setelah memeriksa prototype dari penelitian yang berjudul "Analisis Implementasi Metode Sprint dalam Pengembangan Aplikasi Multiplatform". Ahli menyatakan bahwa prototype dan hasil kegiatan 5 sprint tersebut valid.

\section{SIMPULAN}

Pengembangan aplikasi Fabrik Store dengan menggunakan metode Sprint yang terdiri dari lima tahapan yaitu mapping, sketch, decide, prototype dan test. Metode Pengembangan aplikasi Sprint model meliputi : Pada mapping dilakukan kegiatan Goal mapping danask the expert yang meliputi penentuan goal jangka panjang serta goal mapping dan pembuatan HMW note. Pada sketch dilakukan beberapa kegiatan seperti lighting demo, carasy eight dan pembuatan sketsa solusi dimana tahapan ini dilakukan votinguntuk menetukan sketsa rancangan yang terbaik. Pada decide dilakukan pembuatan storyboard dari hasil voting sketch dimana storyboard menjelasakan alur pengguanaan aplikasi atau biasa disebut navigasi. Pada Prototype dilakukan pembuatan Highfidelity prototype. Pada test dilakukan pengambilan keputusan atau kesimpulan dari hasil responden, dimana decider menyatakan Fabrik Mobile layak untuk masuk ketahapan penulisan kode program (coding).

\section{UCAPAN TERIMA KASIH}

Pada bagian ini, penulis menyampaikan ucapan terima kasihnya kepada sumber pendanaan atau bantuan yang diterima, dan pihak lain memainkan peran penting dalam melaksanakan studi Anda dan / atau menyiapkan naskah jika ada sebelum referensi.

\section{REFERENSI/DAFTAR PUSTAKA}

Czernicki, B. 2009Next-Generation Business Intelligence Software with Silverlight 3, New York: Apress.

Dewi, M. A., Andriani, R. 2017. "Implementasi Scrum Model Development pada Monitoring Inventory Control Cleaning Equipment dan Chemical PT. Explore Global Solution," ULTIMA InfoSys, vol. VIII, no. 2, pp. 112-117.

Keijzer-Broers dan De Reuver. 2016. "Applying Agile Design Sprint Methods in Action Design Research: Prototyping a Health and Wellbeing Platform," Delft University of Technology.

Kemenperin. 2018. "Indonesia Kurang Bahan Baku Tekstil,". [Online, Diakses 17 Juni 2019].

Knapp, Zeratsky, Kowitz, Sprint : How To Solve Big Problems and Test New Ideas in Just Five Days, New York: Simon \& Schuster, 2016.

Muzakir, A., Hidiansah, E. 2018. "Mobile Hybrid Application Sebagai Solusi dalam Pelaporan Bencana Menggunakan Framework Cordova," Jurnal Informatika: Jurnal Pengembangan IT (JPIT), vol. 03, no. 02, pp. 242-248. 
Raubenolt, A. 2016"An Analysis of Collaborative Problem-Solving Mechanisms in Sponsored Projects: Applying the 5-Day Sprint Model," The Journal of Research Administration SRA International, vol. 47, no. 2, pp. 94-111.

Soenarto. 2005. “Metodologi Penelitian” UNY, Yogyakarta, 2005.

Untari, D.,Fajariana, D. E. 2018. "Strategi Pemasaran Melalui Media Sosial Instagram (Studi Deskriptif pada Akun@Subur_Batik),"Widya Cipta,vol.2,no. 2,pp. 271-278.

Tua, B. 2018. Node.js Handbook untuk Pemula, Medan: BonzDev.

Wang dan X. Ai. 2016. "Managing Product Variety on Platform: Product Market Risk and Scope Economies," $13^{\text {th }}$ International Conference on Service Systems and Service Management (ICSSSM)., Chengdu. 